\title{
Temperature Dependence of Viscosities and Potentiometric Titration Behavior of Aqueous Poly(acrylic acid) and Poly(methacrylic acid) Solutions
}

\author{
Masao Sakurai, ${ }^{\dagger}$ Takateru Imai,${ }^{\dagger \dagger}$ Fumitaka Yamashita,${ }^{\dagger \dagger}$ \\ Kunio Nakamura, Tsuyoshi Komatsu, \\ and late Tsurutaro NAKAGAWA \\ Department of Polymer Science, Faculty of Science, Hokkaido University, \\ Sapporo 060, Japan
}

(Received February 10, 1993)

\begin{abstract}
The viscosities of poly(acrylic acid) (PAA) and poly(methacrylic acid) (PMA) have been measured in aqueous $0.25 \mathrm{M} \mathrm{NaCl}$ solutions at $5,15,25,35$, and $45^{\circ} \mathrm{C}$ as a function of various degrees of neutralization. The potentiometric titration data for these polycarboxylic acids in water at 5,25 , and $45^{\circ} \mathrm{C}$ are also reported. Both results indicate that the compact conformation of PMA at low degree of dissociation is more stabilized at lower temperatures. The origin of the hydrophobic interaction has been discussed and it has been suggested that any change of water structure around hydrophobic groups is not required to account for the $\mathrm{pH}$-induced conformational transition of PMA.

KEY WORDS Viscosity / Potentiometric Titration / Poly(acrylic acid) / Poly(methacrylic acid) / Aqueous Solution / Conformational Transition / Hydrophobic Interaction
\end{abstract}

Some synthetic polyelectrolytes, such as poly(methacrylic acid) (PMA), in aqueous solutions undergo a $\mathrm{pH}$-induced conformational transition from a compact coil to an extended coil form at relatively low degrees of ionization, $\alpha$. Such an anomalous behavior was at first described in the study of viscosity and $\mathrm{pH}$ of PMA solution by Katchalsky ${ }^{1}$ and then has attracted the attention of many researchers because of a resemblance to the well-known globular-to-coil transition of proteins.

Katchalsky has attributed the resistance to the chain expansion as being due to van der Waals attraction and especially hydrogen bonding between various parts of the PMA molecules. Arnold ${ }^{2}$ showed that the solution viscosity and $\mathrm{pK}$ of poly(acrylic acid) (PAA) increase monotonously with the increase in $\alpha$, and stated that the reason of the different behavior of two polycarboxylic acid remains obscure, although it could be connected with the greater flexibility of the PAA molecule as compared with that of PMA.

Anufrieva et al. $^{3}$ have explained the stabilization of the compact coil form of PMA from the point of view of the structural change of water around methyl group on PMA molecule, i.e., hydrophobic interaction. This idea has been supported by the studies of solubilization of hydrophobic molecules ${ }^{4}$ and calorimetry. ${ }^{5}$ This appears, at present, to be a most popular interpretation for the conformational transition of PMA and the other polycarboxylic acids.

\footnotetext{
† To whom correspondence should be addressed.

${ }^{\dagger \dagger}$ Present address: Japan Synthetic Rubber Co., Yokkaichi 510, Japan.

${ }^{+\dagger}+$ Present address: Hokusei Gakuen Women's Junior College, Sapporo 064, Japan.
} 
Yamashita and $\mathrm{Kwak}^{6}{ }^{6}$ however, have concluded from their precise heat capacity measurements that there is no evidence of the hydrophobic interactions in the conformational transition behavior of PMA. Recently, on the basis of the fluorescence studies, Bednár et $a .^{7}$ suggested the importance of intramolecular hydrogen bonds between the ionized and unionized carboxyl groups, in addition to the hydrophobic interactions. Thus, the exact nature of the conformational transition is still poorly understood. The hydrophobic interactions through the intermediary of the waterstructural change would be very sensitive to temperature or pressure. In the present study we measured the temperature dependence of viscosities and potentiometric titrations of aqueous PAA and PMA solutions.

\section{EXPERIMENTAL}

\section{Materials}

Purified methacrylic acid was dissolved in water and polymerized with hydrogen peroxide as an initiator in a nitrogen atmosphere. Concentration of monomer was about $20 \mathrm{wt} \%$, that of peroxide $0.6 \mathrm{wt} \%$, the polymerization temperature was $90^{\circ} \mathrm{C}$, and the reaction time was about 2 hours. The gel-like solution was diluted with water and then PMA was precipitated by the addition of concentrated $\mathrm{HCl}$ solution. The polymer obtained was again dissolved in distilled water and purified by dialysis. The molecular weight was estimated to be $7.4 \times 10^{5}$ from the intrinsic viscosity of Na-type polymer in $2 \mathrm{M} \mathrm{NaNO}$ solution at $25^{\circ} \mathrm{C}^{8}$

Commercial product of $25 \%$ aqueous PAA solution was diluted with very dilute $\mathrm{HCl}$ solution and purified by dialysis against distilled water. The molecular weight was $2.4 \times 10^{5}$ from the viscosity measurements of the polymer with degree of neutralization of 0.4 in $0.5 \mathrm{M} \mathrm{NaBr}$ solution at $25^{\circ} \mathrm{C} .^{9}$

The concentrations of the polyacids in aqueous stock solutions were determined by conductometric titrations with a carbonate-free $0.1 \mathrm{M} \mathrm{NaOH}$ solution.

\section{Viscosity Measurements}

By adding a calculated amount of $0.5 \mathrm{M}$ $\mathrm{NaOH}$ solution to the stock solution, we obtained solutions of PAA or PMA with various degrees of neutralization; $\alpha^{\prime}=0,0.1$, $0.2,0.3$, and 0.8 . The viscosities of these polymer solutions containing $0.25 \mathrm{M} \mathrm{NaCl}$ were measured by using Ostwald-type dilution viscometers at $5,15,25,35$, and $45^{\circ} \mathrm{C}$. The viscosities of unionized PMA in $0.002 \mathrm{M} \mathrm{HCl}$ solutions were also measured at 5, 25, and $45^{\circ} \mathrm{C}$. Flow times of water in three viscometers used were $250-300 \mathrm{~s}$ at $25^{\circ} \mathrm{C}$ and a kinetic energy correction could be neglected. The temperature of the thermostat bath was maintained within $0.02^{\circ} \mathrm{C}$ using a thermister temperature controller constructed in our laboratory.

\section{Potentiometric Titrations}

The $\mathrm{pH}$ measurements were made using an Orion Model 801A ion meter equipped with a Denkikagaku MG511 glass electrode and a Horiba $2535 \mathrm{~A}$ calomel electrode connected by a saturated $\mathrm{KNO}_{3}$-agar salt bridge. The titrations were carried out with carbonate-free $0.1 \mathrm{M} \mathrm{NaOH}$ solution under nitrogen atmosphere at 5,25 , and $45^{\circ} \mathrm{C}$. The polyacid concentrations were 4.653 and $4.372 \times 10^{-3}$ monomol $\mathrm{dm}^{-3}$ for PAA and PMA, respectively.

\section{RESULTS AND DISCUSSION}

\section{Potentiometric Titration}

The $\mathrm{pH}$-titration results were expressed in terms of the dependence of an apparent dissociation constant $\mathrm{p} K_{\mathrm{a}}$ on the degree of dissociation $\alpha$, where $\mathrm{p} K_{\mathrm{a}}=\mathrm{pH}+\log [(1-\alpha) / \alpha]$. The results for PAA and PMA solutions at three temperatures are given in Figures 1 and 2 , respectively. It is evident that the $\mathrm{p} K_{\mathrm{a}}$ values for PAA increase monotonously with the 


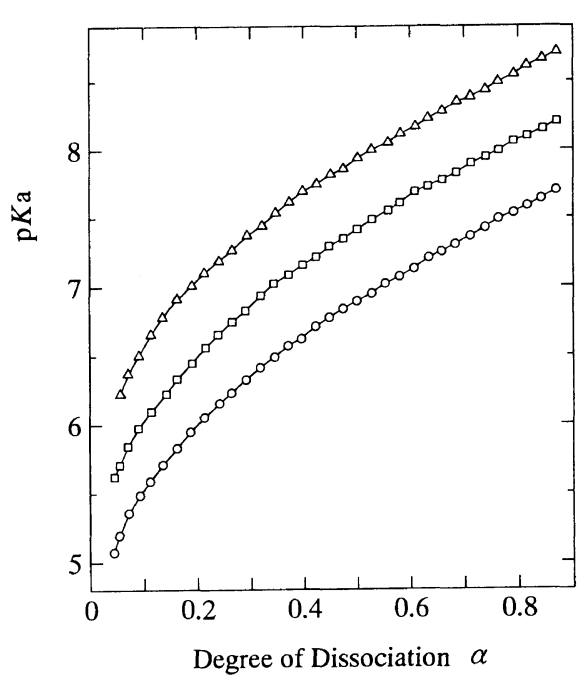

Figure 1. Modified pH-titration curves of poly(acrylic acid) in aqueous solution. $\bigcirc, 5^{\circ} \mathrm{C} ; \square, 25^{\circ} \mathrm{C} ; \triangle, 45^{\circ} \mathrm{C}$. For clarity, the ordinate scale for the data at 25 and $45^{\circ} \mathrm{C}$ has been displaced by 0.5 and $1.0 \mathrm{p} K_{\mathrm{a}}$ unit, respectively.

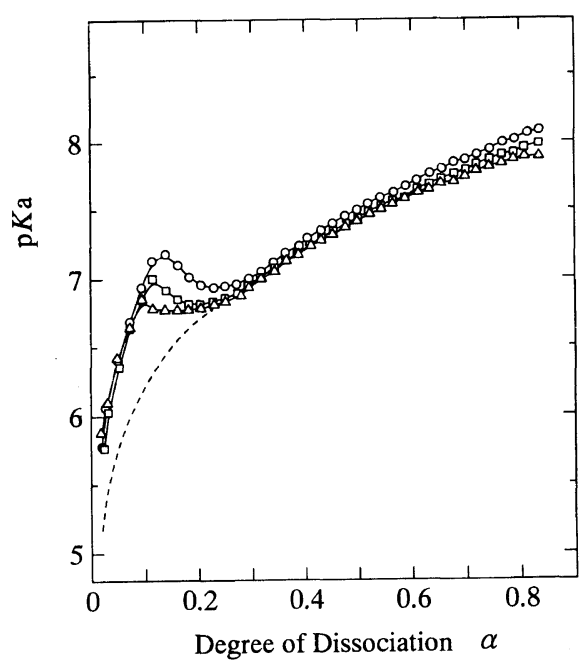

Figure 2. Modified pH-titration curves of poly(methacrylic acid) in aqueous solution. $O, 5^{\circ} \mathrm{C} ; \square, 25^{\circ} \mathrm{C} ; \triangle$, $45^{\circ} \mathrm{C}$. The broken line represents the hypothetical titration curve of the extended coil form at $25^{\circ} \mathrm{C}$.

increase in $\alpha$, while the $\mathrm{p} K_{\mathrm{a}}$ curves for PMA pass through a maximum at low dissociation, dependent on the temperature. The anomalous $\mathrm{p} K_{\mathrm{a}}$ behavior observed for PMA at $\alpha=0-0.3$ has been well-known and in general interpreted in terms of the transition from a compact coil at low $\mathrm{pH}$ to an extended coil form at higher degrees of dissociation of polyacid. As the temperature is decreased, the transition becomes more pronounced and the onset of the transition shifts to higher $\alpha$.

The titration behavior of PMA differs markedly from that of PAA not only in the existence of the conformational transition but aiso in the acid strength. The difference between $\mathrm{p} K_{\mathrm{a}}$ values of PAA and PMA at very low degrees of dissociation is as much as $1 \mathrm{pH}$ unit, that is, the acid strength of PMA is about ten times smaller than that of PAA. This is a clear contrast to the case of corresponding low molecular carboxylic acids: $\mathrm{p} K_{\mathrm{a}}=4.876$ and 4.860 for propionic and isobutyric acids, respectively. ${ }^{10}$ There seems no satisfactory theory to interpret the difference in acid strength of these polycarboxylic acids. It is, however, interesting to note that a more pronounced conformational transition has been observed for polycarboxylic acids having lower acid strength as can be seen from the comparison of the $\mathrm{pH}$ titration behavior of poly(methacrylic acid) with poly(ethacrylic acid), ${ }^{11}$ maleic acid-styrene with maleic acid- $\alpha$-methylstyrene copolymers, ${ }^{12}$ or copolymers of maleic acid and various alkylvinylethers. ${ }^{13}$

The standard free energy change $\Delta G_{t}{ }^{\circ}$ for the transition is given by

$$
\Delta G_{\mathrm{t}}{ }^{\mathrm{o}}=2.303 R T \int_{0}^{1}\left(\mathrm{p} K_{\mathrm{a}}-\mathrm{p} K_{\mathrm{a}}\right) \mathrm{d} \alpha
$$

where $\mathrm{p} K_{\mathrm{a}}^{\prime}$ is the hypothetical value for the extended coil form without the transition. According to the procedure of Leyte and Mandel, ${ }^{14}$ the $\mathrm{p} K_{\mathrm{a}}{ }^{\prime}$ values were estimated by extrapolation of the curve for dissociated extended form at higher $\mathrm{pH}$ region to the lower $\alpha$ region with the aid of the Henderson-Hasselbalch plot. The $\mathrm{p} K_{\mathrm{a}}^{\prime}$ values at $25^{\circ} \mathrm{C}$ are illustrated in Figure 2 as a broken line.

The values of $\Delta G_{t}^{\circ}$ obtained by graphical integration are 670,600 , and $540 \mathrm{~J} \mathrm{~mol}^{-1}$ at 5 , 
25 , and $45^{\circ} \mathrm{C}$, respectively. The error in the $\Delta G_{t}{ }^{\circ}$ estimation is considered to be about $10 \%$. The $\Delta G_{t}{ }^{\circ}$ values estimated in this study are comparable with those found in the literature: $740 \mathrm{~J} \mathrm{~mol}^{-115}$ at $5^{\circ} \mathrm{C}, 710 \mathrm{~J} \mathrm{~mol}^{-116}$ at $11^{\circ} \mathrm{C}$, $720 \mathrm{~J} \mathrm{~mol}^{-116}$ at $18^{\circ} \mathrm{C}, 585,,^{11} 770,{ }^{14}$ and $720 \mathrm{~J} \mathrm{~mol}^{-116}$ at $25^{\circ} \mathrm{C}, 630 \mathrm{~J} \mathrm{~mol}^{-116}$ at $32^{\circ} \mathrm{C}$, $610 \mathrm{~J} \mathrm{~mol}^{-116}$ at $39^{\circ} \mathrm{C}, 690 \mathrm{~J} \mathrm{~mol}^{-117}$ at $45^{\circ} \mathrm{C}$, $640 \mathrm{~J} \mathrm{~mol}^{-115}$ at $50^{\circ} \mathrm{C}$, and $510 \mathrm{~J} \mathrm{~mol}^{-111}$ at $80^{\circ} \mathrm{C}$.

Some scatter of the values among the literature and this study may be in part attributed to the differences of concentrations of polymer or added electrolytes and/or to somewhat different tacticity of the PMA samples used by various authors. Schafer et $a l .{ }^{16}$ have clearly indicated that the increase in ionic strength reduces the $\Delta G_{t}{ }^{\circ}$ values. The tacticity is one of the decisive factors in determining the conformational transition behavior. A marked irreversible titration curve can be observed for isotactic PMA, but not for syndiotactic PMA. ${ }^{18,19}$ It is apparent that isotactic PMA is a weaker acid and exhibits a more pronounced conformational transition than syndiotactic or atactic PMA, ${ }^{20,21}$ the latter was used in the present work.

In spite of the scatter in $\Delta G_{t}{ }^{\circ}$ values, it is evident that the $\Delta G_{t}{ }^{\circ}$ values decrease with the increase in temperature. The larger $\Delta G_{t}{ }^{\circ}$ and higher $\alpha$ of the onset of transition at lower temperature indicate that the compact form of PMA at low ionization region is more stabilized with the decrease in temperature.

\section{Viscosity}

Because of the polyelectrolyte nature of the samples studied, the intrinsic viscosity $[\eta]$ is in general obtained only in the presence of low molecular weight electrolytes. In this study $0.25 \mathrm{M} \mathrm{NaCl}$ aqueous solution was used as a solvent, where the reduced viscosity $\eta_{\mathrm{sp}} / C_{\mathrm{p}}$ can be represented by the well-known relation: $\eta_{\mathrm{sp}} / C_{\mathrm{p}}=[\eta]+k^{\prime}[\eta]^{2} C_{\mathrm{p}}$, where $k^{\prime}$ is Huggins constant and $C_{\mathrm{p}}$ is polymer concentration. The typical examples are shown in Figures 3 and 4

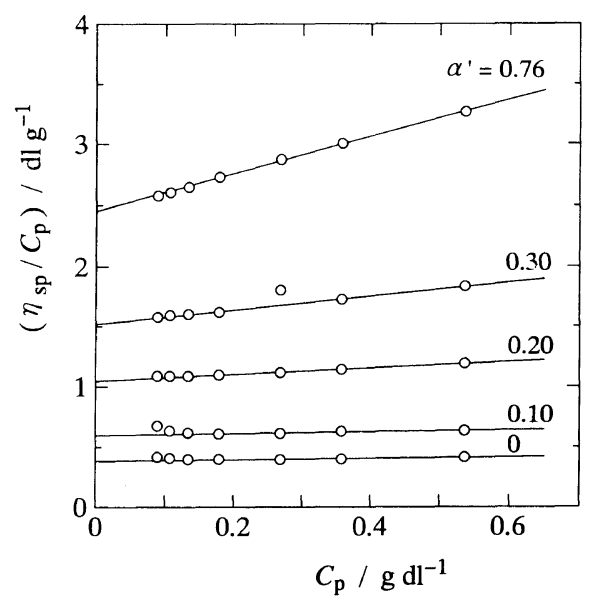

Figure 3. Reduced viscosities of poly(acrylic acid) in $0.25 \mathrm{M} \mathrm{NaCl}$ aqueous solutions of various degrees of neutralization $\alpha^{\prime}$ at $25^{\circ} \mathrm{C}$.

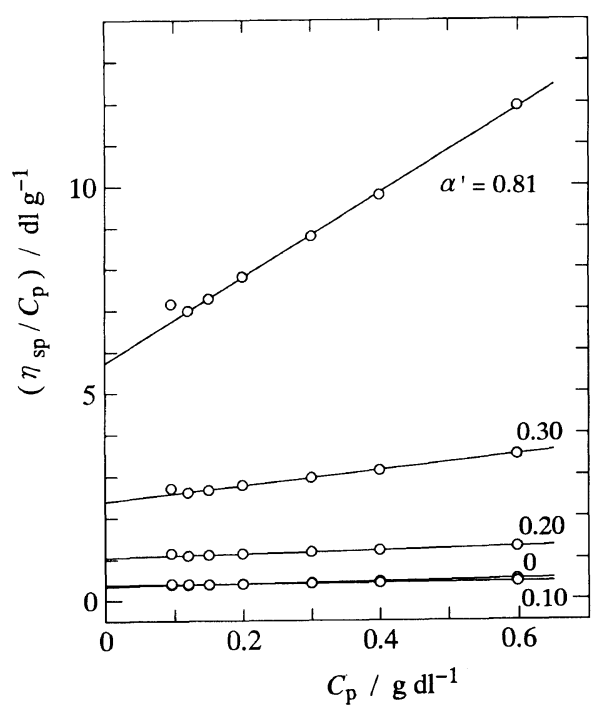

Figure 4. Reduced viscosities of poly(methacrylic acid) in $0.25 \mathrm{M} \mathrm{NaCl}$ aqueous solutions of various degrees of neutralization $\alpha^{\prime}$ at $25^{\circ} \mathrm{C}$.

for PAA and PMA solutions at $25^{\circ} \mathrm{C}$, respectively. In most cases the above linear relation holds and $[\eta]$ values were estimated by the extrapolation to $C_{\mathrm{p}}=0$. We observed that the reduced viscosity increases slightly with decreasing concentration at low $C_{p}$ for both PAA and PMA with very low degree of neutralization $\alpha^{\prime}$. It has been shown that in the 


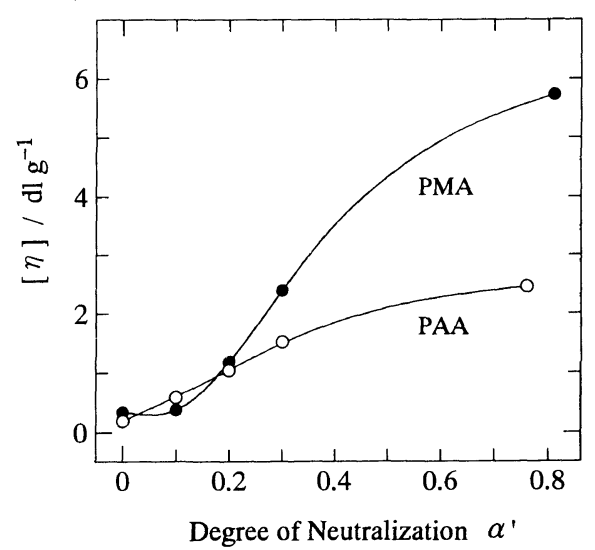

Figure 5. Intrinsic viscosities of poly(acrylic acid) (PAA) and poly(methacrylic acid) (PMA) as a function of degree of neutralization $\alpha^{\prime}$ at $25^{\circ} \mathrm{C}$.

presence of added electrolytes the degree of ionization of unneutralized PMA increases very steeply at lower polymer concentrations. ${ }^{22}$ Such an self-ionization effect results in the increase in viscosity of polyacids even in the presence of large amounts of added electrolytes. In this case a linear extrapolation procedure was employed from the points at higher concentrations.

The dependences of $[\eta]$ on $\alpha^{\prime}$ at $25^{\circ} \mathrm{C}$ are shown in Figure 5 for PAA and PMA solutions. The intrinsic viscosity of PAA increases monotonously with increasing neutralization because of the increase in electrostatic repulsion between charges on polymer chains. As has been well known, on the other hand, for PMA in low $\alpha^{\prime}$ region the polymer coil expands only little up to a critical degree of ionization. This anomalous viscosity behavior can be considered as one of the evidences of the compact-to-extended coil transition of PMA.

The temperature dependences of $[\eta]$ estimated for PAA and PMA are shown in Figures 6 and 7, respectively. With increasing temperature the $[\eta]$ value of PAA with various $\alpha^{\prime}$ increases monotonously or passes through a broad maximum between 15 and $35^{\circ} \mathrm{C}$, whereas [ $\eta]$ decreases for PMA with $\alpha^{\prime}=0$, varies little

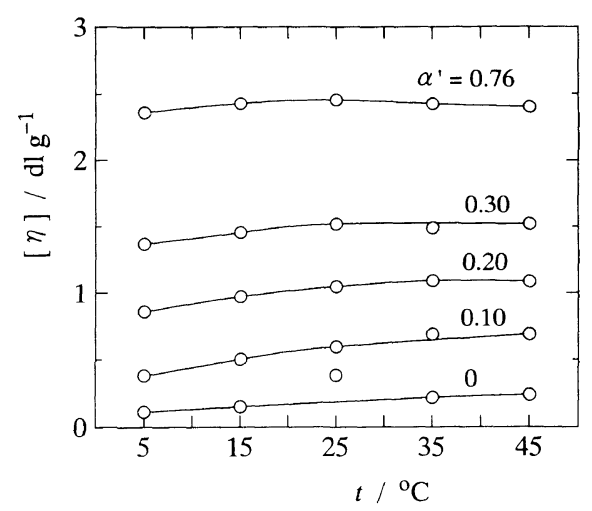

Figure 6. Temperature dependences of the intrinsic viscosities of poly(acrylic acid) of various degrees of neutralization $\alpha^{\prime}$.

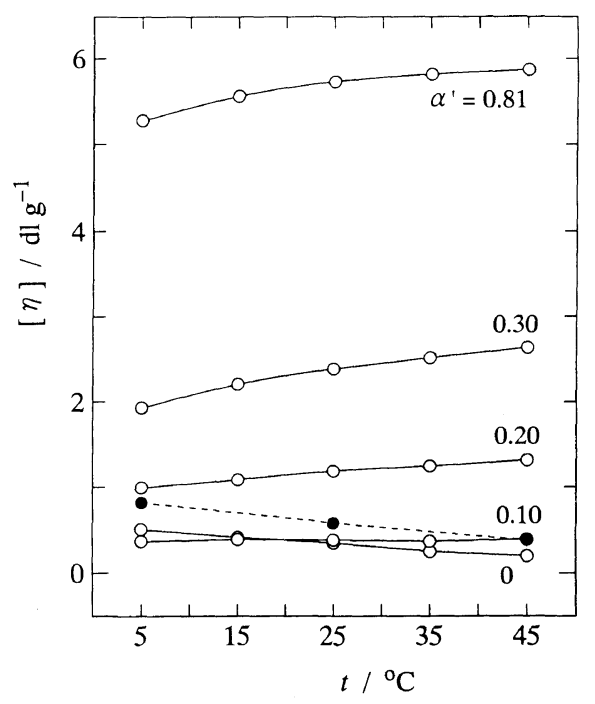

Figure 7. Temperature dependences of the intrinsic viscosities of poly(methacrylic acid) of various degrees of neutralization $\alpha^{\prime}$. The filled circles represent the intrinsic viscosities of undissociated poly(methacrylic acid) in $0.002 \mathrm{M} \mathrm{HCl}$ solution.

for $\alpha^{\prime}=0.1$, and increases in a similar manner to PAA for the larger $\alpha^{\prime}$ samples. In Figure 7 are also included the $[\eta]$ values determined in $0.002 \mathrm{M} \mathrm{HCl}$ solution at 5,25 , and $45^{\circ} \mathrm{C}$, where PMA can be considered to be in an undissociated state. It has already been known that the temperature dependence of $[\eta]$ for the unneutralized PMA is negative. ${ }^{23}$ The conver- 


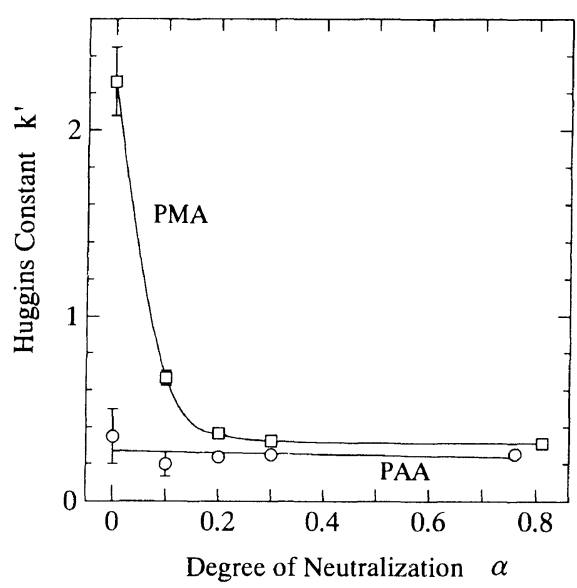

Figure 8. Huggins constants $k^{\prime}$ of poly(acrylic acid) (PAA) and poly(methacrylic acid) (PMA) as a function of degree of neutralization $\alpha^{\prime}$ at $25^{\circ} \mathrm{C}$.

sion of sign of the temperature dependence of viscosity accompanying neutralization of polyacids has been also found for hyaluronic acid. ${ }^{24}$ On the other hand, Sugai and $\mathrm{Ohno}^{25}$ have found the reverse effect for maleic acid-styrene copolymer; the temperature coefficient is positive for the compact form at lower $\alpha^{\prime}$ and negative for the expanded coiled form at higher $\alpha^{\prime}$. The most striking aspect of the present results is that the intrinsic viscosities of PMA at low temperatures decrease with the increase in neutralization up to $\alpha^{\prime}=0.1$. Such an abnormal behavior may be closely related to the origin of the stability of the compact form.

In Figure 8 are illustrated the Huggins constant $k^{\prime}$ determined at $25^{\circ} \mathrm{C}$ for PAA and PMA with various degrees of neutralization. The $k^{\prime}$ values for all PAA samples and for PMA with $\alpha^{\prime}>0.2$ are actually identical to that expected for neutral polymer-good solvent systems: $k^{\prime}=0.2-0.3 .^{26}$ The marked contrast between PAA and PMA is apparent at low ionizations. Extraordinarily high $k^{\prime}$ values at $\alpha^{\prime}=0$ were also observed at the other temperatures, but we could not find an unambiguous regularity on the temperature dependence because some uncertainties in the estimation of concentration dependence of $\eta_{\mathrm{sp}} / C_{\mathrm{p}}$ and $[\eta]$ may increase for low $\alpha^{\prime}$ samples due to self-ionization of the weak polyacid. The values of $k^{\prime}$ estimated for unionized PMA $(\alpha=0)$ in $0.002 \mathrm{M} \mathrm{HCl}$ solution are $0.53,0.54$, and 0.64 at 5,25 , and $45^{\circ} \mathrm{C}$, respectively. Strange to say, these values are much smaller than those for unneutralized PMA $\left(\alpha^{\prime}=0\right)$ but coincide with the $k^{\prime}$ value for $\theta$-condition, ${ }^{26}$ which is known to be $0.002 \mathrm{M} \mathrm{HCl}$ at $30^{\circ} \mathrm{C}$ for PMA. ${ }^{27}$

\section{Conformational Transition of PMA}

In general, the conformational transition of PMA has been interpreted in terms of the competition between electrostatic repulsion between charges on the polymer chain and some attractive interactions such as hydrogen bond between carboxyl or carboxylate groups, van der Waals or hydrophobic interactions between methyl groups. The hydrogen bonding interactions have been proposed by Katchalsky in his explorative study. ${ }^{1}$ Since no transition can be observed for PAA, Mandel and coworkers $^{14,15,28}$ have suggested that the van der Waals forces due to the methyl groups are important.

Since Kauzmann ${ }^{29}$ offered a new concept "hydrophobic bond" to explain the stability of native proteins, much attention has been directed towards assessing the importance of the interactions between hydrophobic molecules or groups in water. This approach has also been used to describe the anomalous solution properties of poly(methacrylic acid). Considering the fact that no conformational transition is observed for PAA which differs from PMA only by nonexistence of $\alpha$-methyl group, it appears to be rather natural to attribute the origin of the transition to the hydrophobic interactions between methyl groups. The conformational transition of copolymers of maleic acid and various hydrophobic co-monomers has also been investigated extensively (see, e.g., ref 6, 17, and 30 and references therein). These studies have clarified that the least hydrophobic ethylene 
copolymer does not bring about any conformational transition and that in general the more hydrophobic the co-monomers the more pronounced is the conformational transition. Therefore, it has been widely accepted that the compact form of polycarboxylic acids is stabilized by the intramolecular hydrophobic interactions of apolar groups on the polymer chain.

However, some experimental results on the confomational transition are in conflict with the explanation based on the hydrophobic interactions. For example, the calorimetric study revealed that the transition to the extended form of PMA is accompanied by an increase in enthalpy and a slight increase in entropy. ${ }^{17}$ As has been pointed out by Mandel et al., ${ }^{15}$ this is exactly the opposite of the expectation based on the hydrophobic bond theory by Kauzmann. He has considered that the hydrophobic interaction is resulted from the melting of so-called iceberg ${ }^{31}$ around non-polar groups in water that is accompanied by positive enthalpy and entropy changes. In other words, the hydrophobic interaction originates essentially from the anomalously large entropy loss accompanying dissolution of nonpolar substances in water. Thus, Kauzmann has explained the very low solubility of hydrocarbons or inert gases in water in terms of this unfavorable entropy effect. It has been often said, therefore, that the hydrophobic interaction is "entropy driven" and, hence, becomes more efficient with increasing temperature. On the contrary, the present study on the temperature dependence of the potentiometric titration behavior and viscosity clearly shows that the conformational transition of PMA is stabilized at lower temperatures. Consequently, it is concluded that the compact form of PMA can not be attributable to the hydrophobic interactions.

In this connection it is relevant to note that the hydrophobic bond theory has been criticized by Shinoda ${ }^{32}$ on the basis of the analysis of the solubility of hydrocarbons in water over a wide range of temperature. He concluded that the slight solubility of nonpolar solutes in water is mainly the effect of a large positive enthalpy of mixing, not the entropy effect and the solubility of nonpolar molecules in water must be increased by the iceberg formation. Ramadan et al. ${ }^{33}$ reached the same conclusion from the study of thermodynamic transfer function of argon from cyclohexane to water and to hydrazine. From this point of view, recently Privalov and Gill ${ }^{34}$ have interpreted the unfolding of the compact structure of protein at low temperature, i.e., cold denaturation. He wrote that "the stabilization of the compact state of a protein, usually attributed to hydrophobic interaction, is primarily due to van der Waals interactions between the protein nonpolar groups, and the contribution of water solvation by these group, in spite of the widely held opinion, actually destabilizes the compact state."

The modification of water structure like iceberg formation would be accompanied by an adequate change in various partial molar quantities, especially partial molar heat capacity. Precise measurements of the partial molar volumes and heat capacities at $25^{\circ} \mathrm{C}$ by Yamashita and Kwak, ${ }^{6}$ however, revealed that these partial molar quantities of PMA vary monotonously with ionization, just like PAA. That is, the conformational transition of PMA does not accompanied by any significant change of partial molar quantities, although obvious transitions in partial molar volume and heat capacity can be observed for copoly(maleic acid-styrene). This situation remains unaltered in the partial molar volume behavior at lower or higher temperatures. ${ }^{35}$ These results indicate that the conformational transition of PMA can not be ascribed to the interactions through the intermediary of structural change of water around hydrophobic groups.

It is well known that the aqueous PMA solution exhibits a LCST (lower critical solution temperature) type phase diagram ${ }^{36}$ and gelation takes place for the concentrated 
aqueous solution with increasing temperature. ${ }^{37}$ These phenomena are often observed for aqueous solutions of solutes consisting of weak polar group and adequately hydrophobic group, and the hydrophilic-hydrophobic balance is generally a dominant factor determining the LCST. ${ }^{38}$ Such a solubility behavior may influence the temperature dependence of solution viscosity. That is, with increasing temperature the decreased solubility of unionized PMA in water may bring about the reduction of the solution viscosity as is illustrated in Figure 7. The abnormally large Huggins constant $k^{\prime}$ found for slightly dissociated PMA described in Figure 8 may indicate that significant intermolecular interactions can take place even in these dilute solutions due to decreased solute-solvent interactions. $^{26,39}$

Wright and coworkers ${ }^{19,21}$ have suggested that the importance of the effect of ionic hydrogen bond formation on the conformations of partly ionized poly(methacrylic acid). This hydrogen bond results from essentially geometrical restriction of polymer chain and therefore such a hydrogen bond formation can not expected for more flexible PAA. From the computations of energies of accessible dyad, furthermore, they have shown that the conformational transition behavior of PMA can be explained by consideration of the rotational states of methyl and methylene groups rather than by intramolecular attractions such as hydrophobic interactions or hydrogen bonding. ${ }^{40}$ The importance of geometrical constraints has also been revealed by the conformational studies for various maleic acid copolymers. ${ }^{12,13}$

The interpretation of the origin of the conformational transition of PMA in terms of the local geometry of the polymer chain seemed to us at present the most reasonable. In addition, ionic hydrogen bonding may contribute to the stabilization of the compact form. The decrease in the intrinsic viscosity of PMA accompanying ionization during the initial stage of neutralization at lower temperatures (Figure 7) can be interpreted in terms of such strong attractive force only. The hydrogen bond interaction becomes to be weakened as the temperature is increased. This may also explain the anomalous $\mathrm{p} K_{\mathrm{a}}$ change at lower temperatures, i.e., the $\mathrm{p} K_{\mathrm{a}}$ values in the transition region decrease (acid strength increases) with increasing ionization in competition with the increase in electrostatic repulsion (Figure 2).

Acknowledgment. The authors wish to thank Professor Nobumichi Ohno, Akita National College of Technology, for his helpful discussions.

\section{REFERENCES}

1. A. Katchalsky, J. Polym. Sci., 7, 393 (1951).

2. R. Arnold, J. Colloid Sci., 12, 459 (1957).

3. E. V. Anufrieva, T. M. Birshtein, T. N. Nekrasava, O. B. Ptitsyn, and T. V. Sheveleva, J. Polym. Sci., C, 16, 3519 (1968).

4. G. Barone, V. Crescenzi, B. Pispisa, and F. Quadrifoglio, J. Macromol. Chem., 1, 761 (1966).

5. V. Crescenzi, F. Quadrifoglio, and F. Delben, $J$. Polym. Sci., A-2, 10, 357 (1972).

6. F. Yamashita and J. C. T. Kwak, J. Polym. Sci., Polym. Phys., 25, 1395 (1987).

7. B. Bednář, J. Trněná, P. Švoboda, S. Bajda, V. Fidler, and K. Procházka, Macromolecules, 24, 2054 (1991).

8. R. Arnold and S. R. Caplan, Trans. Faraday Soc., 51, 857 (1955).

9. I. Noda, T. Tsuge, and M. Nagasawa, J. Phys. Chem., 74, 710 (1970).

10. A. Albert and E. P. Serjeant, "Ionization Constants of Acids and Bases," Methuen \& Co., London, 1962.

11. D. E. Joyce and T. Kurucsev, Polymer, 22, 415 (1981).

12. N. Ohno, Polym. J., 13, 719 (1981).

13. C. Villiers and C. Braud, Nouv. J. Chim., 2, 33 (1978).

14. J. C. Leyte and M. Mandel, J. Polym. Sci., A, 2, 1879 (1964).

15. M. Mandel, J. C. Leyte, and M. G. Stadhouder, J. Phys. Chem., 71, 603 (1967).

16. O. Schafer and H. Schonert, Ber. Bunsenges. Phys. Chem., 73, 94 (1969).

17. V. Crescenzi, "Polyelectrolytes," E. Selegny, Ed. D. Reidel Publishing Co., Dordrecht, Holland, 1974, p 115 .

18. J. C. Leyte, H. M. R. Arbouw-van der Veen, and L. H. Zuiderweg, J. Phys. Chem., 76, 2559 (1972). 
19. S. M. Towlson and P. V. Wright, Polym. Comm., 24, 79 (1983).

20. M. Nagasawa, T. Murase, and K. Kondo, J. Phys. Chem., 69, 4005 (1965).

21. J. N. Davenport and P. V. Wright, Polymer, 21, 287 (1980).

22. M. Sakashita, T. Komatsu, and T. Nakagawa, Nippon Kagaku Kaishi, 751 (1975).

23. A. Silberberg, J. Eliassaf, and A. Katchalsky, $J$. Polym. Sci., 23, 259 (1957).

24. R. L. Cleland, Biopolymers, 18, 1821 (1979).

25. S. Sugai and N. Ohno, Biophys. Chem., 11, 387 (1980).

26. I. Dort, Polymer, 29, 490 (1988).

27. A. Katchalsky and H. Eisenberg, J. Polym. Sci., 6, 145 (1951)

28. M. Mandel and M. G. Stadhouder, Makromol. Chem., 80, 141 (1964).

29. W. Kauzmann, Adv. Protein Chem., 14, 1 (1959).

30. N. Ohno and S. Sugai, J. Macromol. Sci., Chem.,
A27, 861 (1990).

31. H. S. Frank and M. W. Evans, J. Chem. Phys., 13, 507 (1945).

32. K. Shinoda, J. Phys. Chem., 81, 1300 (1977); "Youeki to Youkaido,” 3rd ed, Maruzen, Tokyo, 1991.

33. M. S. Ramadan, D. F. Evans, and R. Lumry, J. Phys. Chem., 87, 4538 (1983).

34. P. L. Privalov and S. J. Gill, Adv. Protein Chem., 39, 191 (1988).

35. M. Sakurai, M. Tanaka, and K. Nakamura, unpublished results.

36. J. Eliassaf and A. Silberberg, Polymer, 3, 555 (1962).

37. K. Nakamura, T. Itoh, M. Sakurai, and T. Nakagawa, Polym. J., 24, 1419 (1992).

38. K. F. Mueller, Polymer, 33, 3470 (1992).

39. I. Hernández-Fuentes, M. G. Prolongo, R. M. Masegosa, and A. Horta, Eur. Polym. J., 18, 29 (1982).

40. S. M. Towlson and P. V. Wright, Polymer, 27, 417 (1986). 